\title{
Rosario Ferré, Maldito amor y otros cuentos. Pról., biblio. y notas de Dianna Niebylski. México, FCE, 2006. (Colec. Aula Atlántica)
}

Dentro del catál ogo del Fondo de Cultura Económica se encuentra una colección, "Aula Atlántica", de mucha utilidad para los profesores de literatura en la que se han editado autores como J osé Donoso, Antonio Muñoz Molina, Pedro Sal inas o Rosario Ferré, cuyo volumen nos ocupa en estas líneas. La característica de estos libros según su coordinador, J ulio Ortega, es la de ser "un lugar para el encuentro detodas las orillas delalengua: América Latina, el Caribe, España, Estados Unidos". Como Centro en el cual difundimos el español y su cultura, es de suma importancia tener la referencia de estos libros "compilados por especialistas universitarios" que abren "perspectivas capaces de renovar el gusto por la lectura".

De tal modo, Dianna Niebylski ha preparado la edición de textos narrativos de Rosario Ferré, una de las voces más frescas de la literatura escrita por mujeres en Hispanoamérica. La estructura del volumen debería servir de modelo para el resto de la colección —pues he notado que cada especial ista ofrece elementos distintos en los distintos ejemplares de "Aula Atlántica"-, ya que incluye además de un enterado prólogo, una cronología de la vida de Ferré, una guía de temas de investigación por obra incluida ("La muñeca menor", "Maquinolandera", Maldito amore "I solda en el espejo"), una bibliografía de y sobre la narradora puertorriqueña, un apéndice con una selección de comentarios críticos expresados por la autora en diversas fuentes y un glosario. Todos estos apartados hacen de la edición de esta obrauna verdadera veta de conocimiento sobrela creación literaria de Rosario Ferré.

El empleo de negritas para señalar en los textos aquel vocabulario de difícil comprensión, ya sea por tratarse de regionalismos o palabras de uso poco frecuente, facilita la lectura de los estudiantes extranjeros que realizan sus primeras aproximaciones a la literatura en español. Me parece un recurso excepcional que debería ser retomado en el resto de la colección.

La hechura del libro es de una calidad impecable. Los forros de pasta dura, las guardas y el papel escogido para la impresión dan constancia de la idea del libro como un objeto que perdura. Así "Aula Atlántica" nos revela su voluntad de trascendencia, no sólo con la selección de autores imprescindibles en lengua españolasi no por lo perdurable del ejemplar en sí mismo. El caso de Bitácora del crucede Guillermo Gómez-Peña, escritor mexicano radicado en Estados Unidos, es mucho más ilustrativo, pues es una obra que integra su diseño editorial con la propuesta literaria. 
La profesora Dianna Niebylski realizó un trabajo espléndi do como mediadora entre los lectores y la obra de Rosario Ferré, al señalar aspectos rel evantes de los textos narrativos de esta autora, esencial para comprender el proceso mediante el cual las mujeres latinoamericanas tomaron la voz e iniciaron una refocalización de aquellos aspectos de la vida que fueron relatados con una perspectiva diferente.

No obstantequela aperturaal universo femenino en la literatura iberoamericana se dio desde antes de la mitad del siglo XX con autoras como María Luisa Bombal, Carmen Laforet, Si lvina Ocampo o Rosario Castellanos, por señalar al gunas, es importante apreciar la propuesta de escritoras de la generación de Rosario Ferré como Cristina Peri Rossi o Luisa Valenzuela, quienes afianzan en nuestras letras ese particular punto de vista ya sin percibirse como casos excepcionales.

Mención especial merece el apartado de "Temas de investigación" ya que no sól o apunta las directrices para posibles estudios de las obras, si no que aproxima a los textos mediante la anotación de al gunas semejanzas con otros escritoresy la puntualización de al gunas características primordiales del título en cuestión.
Como cualquier otra antología puede presentarse discrepancias en la selección de las narraciones, por ejemplo, yo incluiría "La bella durmiente" un cuento que aparece en Papeles de Pandora(1976) pues ahí se aprecia la dinámica de la literatura de aquella época que intentaba jugar con los distintos tipos de discurso (cartas, notas de periódico, etc.), además de ser representativo de la temática de la autora. Sin embargo, la reedición de un clásico de las letras en español como Maldito amor (1986) compensa la ausencia de aquel otro texto.

De cualquier manera, este volumen de la colección "Aula Atlántica" dedicado a la obra de Rosario Ferré es al tamente recomendable en el medio universitario, ya que en él se aprecia el valor de los estudios literarios que tratan no sólo de atraer más lectores sino de conseguir lecturas más profundas de las obras.

Horacio Molano Nucamendi CEPE-UNAM 
Decires Revista del Centro de Enseñanza paraExtranjerosse terminó de imprimir en lostalleres de Navegantes dela comunicación gráfica S.A. deC.V., ubicados en Pascual Ortíz Rubio, núm. 40, Col. San Simón Ticumac, México, D.F., C.P. 03600, en el mes de noviembre de 2007. El tiro consta de 500 ejemplares.

Diseño de portada: Erandi Hernández Serra. Diseño deinteriores, corrección y cuidado de Ia edición: Sol Eréndira López Valdez. Formación de interiores: Yvetthe Paola Rendón Rahal. 